\title{
Adsorption of Phenol Using 8-Hydroxyquinoline Treated and Untreated Tea Waste
}

\author{
Mitiku Tamene and Khalid Siraj* \\ Department of Chemistry, Jimma University, Ethiopia
}

Submission: February 19, 2019; Published: March 18, 2019

*Corresponding author: Khalid Siraj, Department of Chemistry, College of Natural Sciences, Jimma University, Jimma, Ethiopia

\begin{abstract}
Phenol compounds found in wastewaters of various industries such as petroleum refining, coal conversion, plastic, textiles, iron and steel manufacturing units. Remediation of phenols and its derivatives from contaminated water before discharging is essential, as they are toxic for aquatic organisms. This work is an attempt to remove phenol from aqueous solution applying the adsorption technique using locally available and eco-friendly tea waste adsorbent. The batch adsorption experiment was performed on different concentrations. Langmuir and Freundlich isotherms were applied to confirm the adsorption model. The data obtained found to be best fitted to the Langmuir isotherm. The kinetic study for the adsorption process were performed by checking various models and the data obtained show that the pseudo-second-order model fit well for both 8-HQ treated and untreated powdered tea waste adsorbent.
\end{abstract}

Keywords: Phenol; 8-hydroxyquinoline; Adsorption; Kinetics; Langmuir and Freundlich isotherm

\section{Introduction}

Water is an essential resource for the existence of all life forms. Freshwater is important for human and aquatic organisms and for all activities of all living beings; but they are limited due to the increasing population, urbanization and climate changes. This scarcity was due to water pollution that caused by the discharge of untreated or partially treated industrial effluents into the natural ecosystem, posing serious problems. Thus, these industrial effluents, containing several organic and inorganic chemicals as -phenols, formaldehyde, dyes, and heavy metals are the major water pollutants [1].

Aromatic hydrocarbons are one of the common contaminants of groundwater originating from coal gasification, oil refining process, wood treatment process, fires of forests automobile exhausts and disposal of oils and fuels. Many of these compounds are reported ${ }_{\alpha}$ to be toxic, carcinogenic and tend to accumulate in the aquatic organisms even present in low concentrations. The presence of heteroatom in them makes them more soluble than their homocyclic analogs [2-5]. One of the aromatic organic compounds is phenol $\left(\mathrm{C}_{6} \mathrm{H}_{5} \mathrm{O}\right)$ white crystalline solid that is volatile. It consists of phenyl $\left(\mathrm{C}_{6} \mathrm{H}_{5}-\right)(-\mathrm{OH})$ groups which was first extracted from coal tar. It is an important industrial commodity as a precursor to many materials and useful compounds. Their major use involves its conversion to plastic or relates materials $[6,7]$.

Beside their usage phenol and its chemical derivative has a toxic effect on the aquatic organisms and humans. Since phenol and its derivatives are harmful to living even at low concentrations, they known as dubious pollutants. Phenols and its deriv atives removal study have been reported by various researchers [8-10].

Several methods for organic pollutants removal from wastewaters, such as precipitation, solvent extraction, and adsorption are usually applied. Adsorption is one of the respective methods for wastewater treatment due to its several advantages such as high efficiency, low cost, simple application and easy recovery of adsorbent [11]. Recently, researchers reported the potential use of tea waste generated from the cafeteria as an adsorbent for removal of heavy metal from aqueous solution [9,12-14].

In this work tea waste collected from the local cafeteria used as an adsorbent for the removal of phenol from aqueous solution. Collected tea wastes were used as an untreated and 8-Hydroxyquinoline treated powder for the potential removal process.

\section{Materials and Method}

The following chemicals and materials used in this work. Hydrochloric acid, $\mathrm{HCl}$, Sodium hydroxide, $\mathrm{NaOH}$, Phenol, $\mathrm{C}_{6} \mathrm{H}_{5} \mathrm{OH}$, and 8-Hydroxyquinoline (99\% Sigma Aldrich), Graduated cylinder, Oven drier, Digital electronic balance, Potentiometer (microprocessor pH meter, pH 211, HANNA), mortar and Pastel, sieve $150 \mu \mathrm{m}$ size, UV-Vis. Spectrophotometer (JENWAY 6705) and Scanning electron microscope (Model JSM 6510LV, JEOL Japan).

\section{Experimental procedure}

Preparation of adsorbent: The tea waste used as an adsorbent was collected from different cafeterias of Jimma town, 
Southwestern, for the removal of phenol from aqueous solution. The collected tea waste washed with tap water followed by drying under sunlight. Then the dried tea waste was powdered to mesh size $150 \mu \mathrm{m}$ and washed with distilled water until neutral $\mathrm{pH}$ was observed then kept for drying in an oven at $110^{\circ} \mathrm{C}$. The dried tea waste was now separated into two halves, then one half was treated with an 8-HQ solution; while other part left untreated. Both parts of tea waste were kept in the sample bottle separately for the further experiment.

Preparation of stock solution: A saturated solution of 8-HQ was prepared by adding an appropriate quantity in $1000 \mathrm{ml}$ of distilled water, sonicating for $2 \mathrm{hr}$ and then stirred with a magnetic stirrer for another $2 \mathrm{hr}$. The solution was then filtered to remove the undissolved 8-HQ. Four standard solutions $(10 \mathrm{ppm}, 15 \mathrm{ppm}$, $20 \mathrm{ppm}$, and $25 \mathrm{ppm}$ ) were prepared by adding $0.01 \mathrm{gm}, 0.015 \mathrm{gm}$, $0.02 \mathrm{gm}$ and $0.025 \mathrm{gm}$ of phenol to $1 \mathrm{~L}$ of distilled water respectively.

Preparation of treated tea waste adsorbent: $10 \mathrm{gm}$ of dried tea waste powdered was taken into round bottom flask and treated with 8-HQ solution then kept into water bath shaker for $24 \mathrm{hrs}$, after that the solution was taken out from the shaker. The solution was then filtered with filter paper and the filtrate washed until excess 8-HQ was removed.

Calibration of phenol: $1 \mathrm{gm}$ of powdered tea waste was weighted and added into four shaking bottles; followed by addition of $100 \mathrm{ml}$ of $(0.01 \mathrm{M}, 0.015 \mathrm{M}, 0.02 \mathrm{M}$, and $0.025 \mathrm{M})$ in each shaking bottle. The sample was shaken for $65 \mathrm{~min}$ before filtration. The filtered sample was calibrated by UV-Vis spectrophotometer. Maximum absorption was obtained at $285 \mathrm{~nm}$.

\section{Adsorption isotherm}

In a solid-liquid system, adsorption results in the removal of solutes from solution by accumulating at a solid surface. The solute remaining in the solution reaches a dynamic equilibrium with that adsorbed on the solid phase. The amount of adsorbate that can be taken up by an adsorbent as a function of both temperature and concentration of adsorbate, and the process, at a constant temperature, can be described by an adsorption isotherm according to the general Eq. (1): In this study, the extent of phenol adsorption capacity at equilibrium, $q_{e}(\mathrm{mg} / \mathrm{g})$, was calculated

$$
\begin{aligned}
& q_{e}=\frac{\left(C_{o}-C_{e}\right) V}{W} \\
& q_{t}=\frac{\left(C_{o}-C_{t}\right) V}{W}
\end{aligned}
$$
(3):

The percentage of phenol removal was calculated using, Eq.

$$
\text { (\%) Adsorption }=\frac{C_{o}-C_{e}}{C_{o}} \times 100
$$

$C_{0}$ corresponds to the initial concentration of $\mathrm{C}_{6} \mathrm{H}_{5} \mathrm{OH}$, and $C_{\mathrm{e}}$ (mg/g) corresponds to the concentration of phenol at equilibrium. $V(\mathrm{~L})$ is the volume of the solution, and $W(\mathrm{~g})$ is the mass of the dry adsorbent.

\section{Result and Discussion}

\section{Calibration of phenol}

Calibration curve was plotted for the solution of phenol at different concentrations shows the maximum peak at $285 \mathrm{~nm}$. At the same wavelength, the different absorbance of the $\mathrm{C}_{6} \mathrm{H}_{5} \mathrm{OH}$ solution formed due to the concentration difference, as shown in Figure 1 (a \& b).

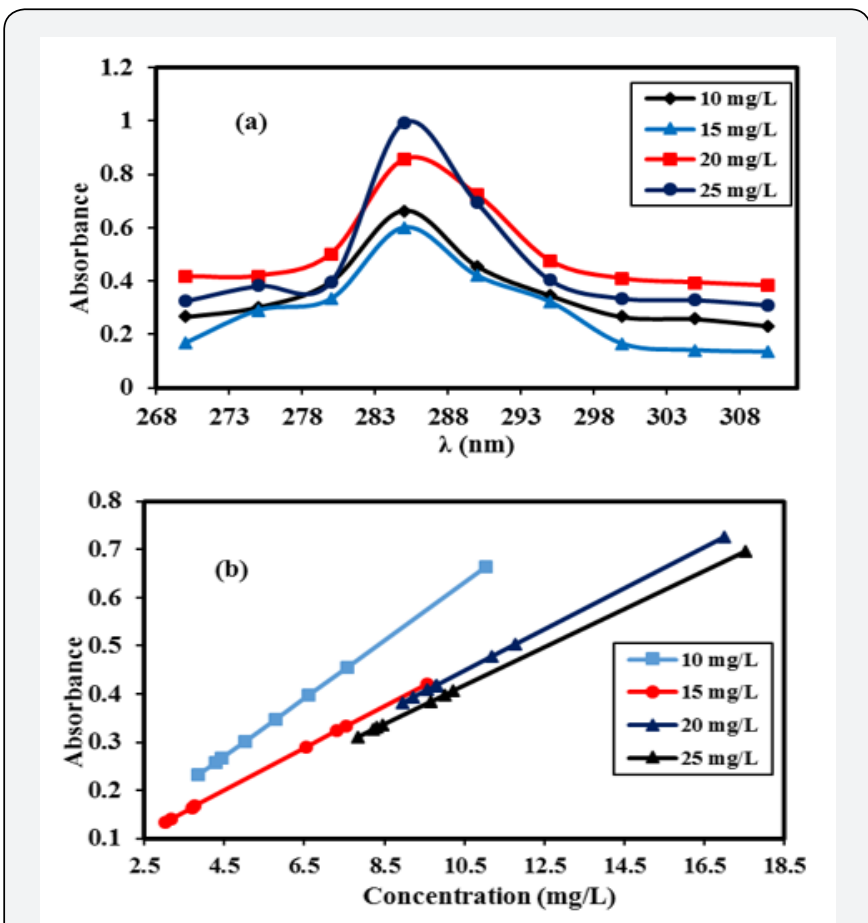

Figure 1: (a) \& (b) shows Calibration of phenol concentration in aqueous solution.

\section{SEM micrograph}

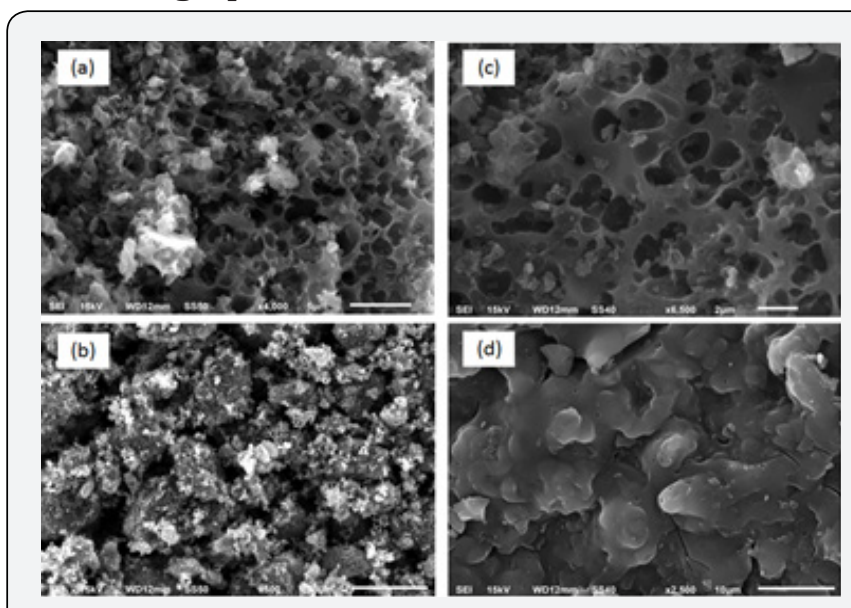

Figure 2: SEM micrographs of untreated and treated tea waste powder (a, b) Untreated tea waste and loaded with phenol; (c, d) Treated tea waste and load with phenol.

Figure 2 ( $a$ \& b) depict the SEM micrographs for tea waste untreated powder before and after phenol adsorption it is evident from the figure that the surface is porous for both treated and untreated tea waste powder. However, apparently this porosity was 
shown disappeared in Figure 2 (c \& d). This may be due, to the fact that diffusion of phenol on to the surface of the adsorbent might have occurred for adsorption [9].

\section{Effect of Initial concentration on contact time for the adsorption of phenol}
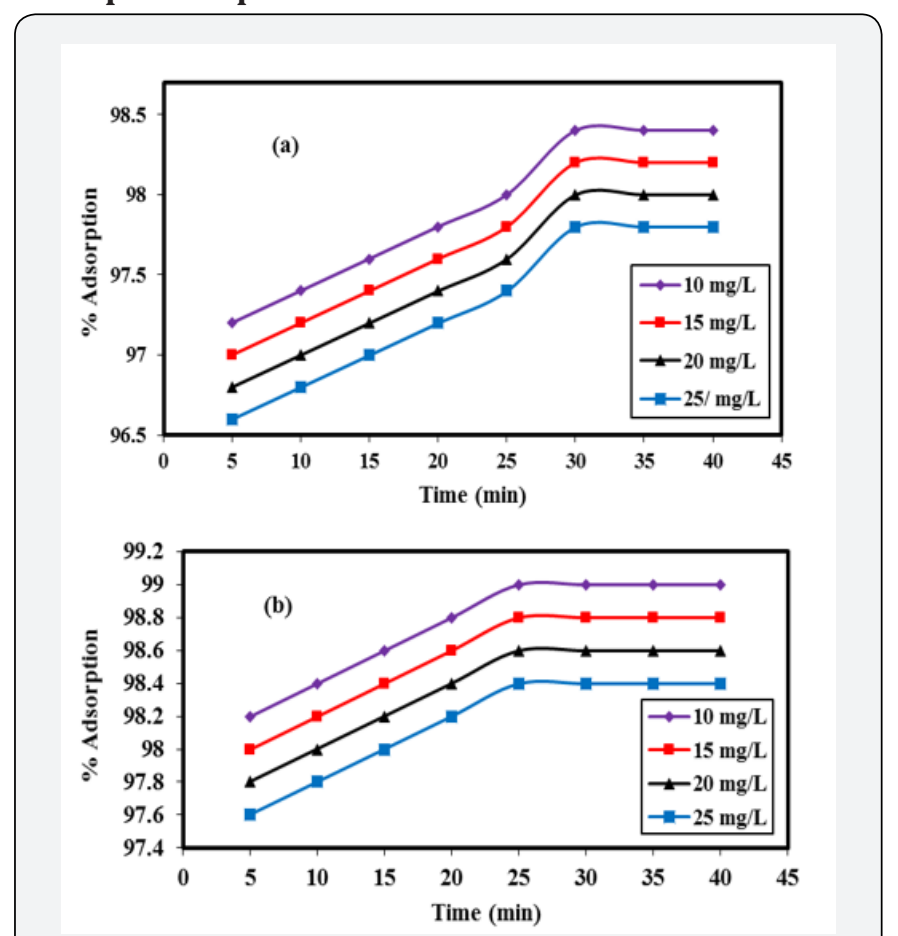

Figure 3: Effect of initial concentration on contact time for the adsorption of phenol at 303K; (a) untreated and (b) 8-HQ treated tea waste.

Time is one parameter that has an influence on surface property of an adsorbent. This effect of time was observed at which adsorbent and solution exist together. As the solution stays for a longer time by shaking with an adsorbent, the number of particles of solute adsorbed to the surface increases. More attachment of solute particles to the adsorbent surface increases the percent of adsorption. Also, modification of the surface increases the percent of adsorption by increasing the surface of the adsorbent. Figure 3 below is showing time influence and difference of percent adsorption of treated and untreated tea waste.

\section{Adsorption isotherm study}

Adsorption isotherm is a basic requirement for the design of an adsorption system. The adsorption mechanism was investigated using Langmuir and Freundlich models. The two models differ from each other in their assumption concerning of existence of fine adsorption capacity [15]. Langmuir isotherm describes quantitatively for the formation of a monolayer on the outer surface of the adsorbent and after that, no further adsorption takes place, Figure 4a. The Langmuir isotherm is valid for monolayer adsorption onto the surface contain a fine number of the identical site [16-20].

The linear form of Langmuir isotherm is given by the following equation.

$$
\frac{C_{e}}{q_{e}}=\frac{1}{q_{m} b_{L}}+\frac{C_{e}}{q_{m}}
$$

Where $\mathrm{q}_{\mathrm{e}^{\prime}}$ and $\mathrm{q}_{\max }$ are equilibrium and maximum uptake capacity $(\mathrm{mg} / \mathrm{g})$ respectively, $\mathrm{b}_{\mathrm{L}}$ is related to the free energy of adsorption and represent the Langmuir adsorption constant, $\mathrm{C}_{\mathrm{eq}}$ is the equilibrium adsorbate concentration in morality. The Langmuir constant that is, related to the maximum capacity $\left(\mathrm{q}_{\max }\right)$ and energy adsorption $\left(b_{L}\right)$, was calculated from the slope \& intercept of linear plot $\mathrm{C}_{\mathrm{e}} / \mathrm{q}_{\mathrm{eq}}$ versus $\mathrm{C}_{\mathrm{eq}}$.

The essential characteristics of the Langmuir equation can be expressed in terms of a dimensionless factor, $\mathrm{R}_{\mathrm{L}}$ that is given by (Table 1)

$$
R_{L}=\frac{1}{1+b_{L} C_{O}}
$$

Where $b_{L}$ is the Langmuir constant and $C_{0}$ is the initial concentration of the adsorbate in solution. The values of $\mathrm{R}_{\mathrm{L}}$ indicates the type of isotherm to be irreversible $\left(R_{L}=0\right)$, favorable $\left(0<R_{L}<1\right)$, linear $\left(R_{L}=1\right)$, or unfavorable $\left(R_{L}>1\right)$. The value of $R_{L}$ is found to be $1.588 \times 10^{-4}$ and $5.026 \times 10^{-4} \mathrm{mg} / \mathrm{L}$ at $303 \mathrm{~K}$ for untreated and treated tea waste adsorption experiment respectively. This indicates that adsorption of phenol is favorable on both 8-HQ treated and untreated tea waste adsorbent.
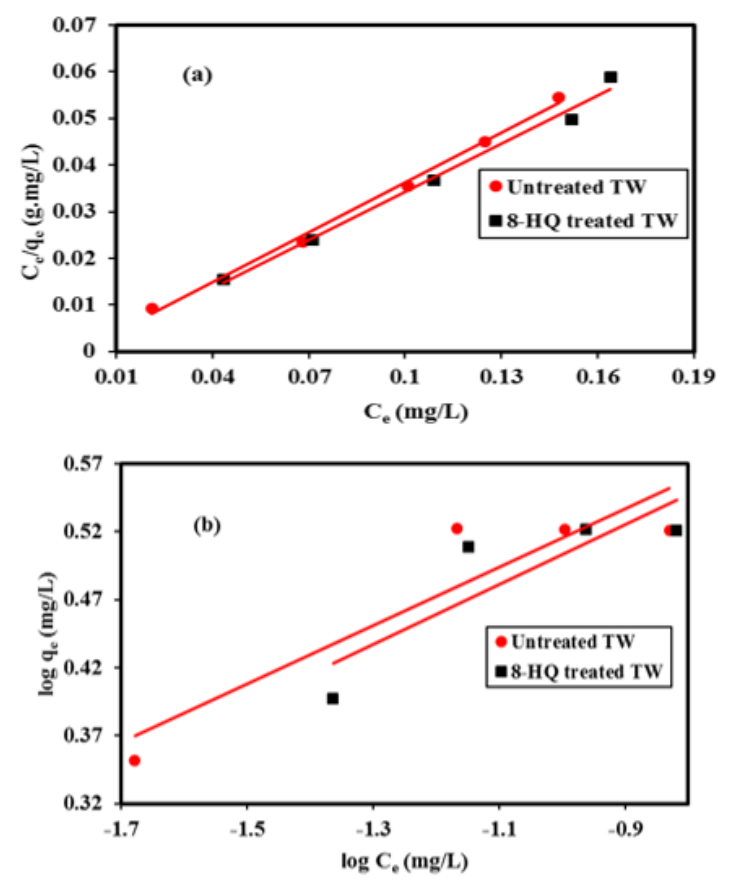

Figure 4: Adsorption isotherm model of phenol onto $8-\mathrm{HQ}$ treated and untreated tea waste; (a) Langmuir (b) Freundlich.

Freundlich adsorption isotherm, Figure 4b commonly used to describe the characteristic for the heterogamous surface [21-24]. The linear form of the Freundlich given as the following equation.

$$
\log q_{e}=\log K_{F}+\frac{1}{n} \log C_{e}
$$

Where $\mathrm{q}_{\mathrm{e}}$ is the adsorption density ( $\mathrm{mg} / \mathrm{g}$ ), $\mathrm{C}_{\mathrm{e}}$ is the concentration of the adsorbate in solution at equilibrium $(\mathrm{mg} / \mathrm{L}) ; \mathrm{K}_{\mathrm{F}}$ and 
$1 / \mathrm{n}$ are the Freundlich constants. The plot of $\log \mathrm{q}_{\mathrm{e}}$ versus $\log \mathrm{C}_{\mathrm{e}}$ yields a straight line indicating to obey a Freundlich adsorption isotherm.

Table 1: Isotherm parameters for Phenol adsorption on modified and unmodified Tea Waste prepared adsorbent at room temperature.

\begin{tabular}{|c|c|c|}
\hline \multirow{2}{*}{ Adsorption Isotherm \& Constants } & \multicolumn{2}{|c|}{ Values } \\
\cline { 2 - 3 } & UTW & 8-HQTW* \\
\hline Langmuir & 2.801 & 2.906 \\
\hline qm (mg/g) & 629.234 & 1989.406 \\
\hline bL (L.mg-1) & 0.997 & 0.995 \\
\hline R2 & 1.588 & 5.026 \\
\hline RL.10-4(mg/L) & & \\
\hline Freundlich & 0.381 & 0.394 \\
\hline n & 2.073 & 2.063 \\
\hline Kf & 0.749 & 0.855 \\
\hline R2 &
\end{tabular}

UTW$^{*}$-Untreated Tea Waste; 8-HQTW*- 8-HQ treated Tea Waste.

This isotherm does not predict any saturation of the sorbent by the sorbate; thus, mathematically infinite surface coverage is predicted, indicating multilayer adsorption on the surface. Freundlich adsorption isotherm gives an expression encompassing the surface heterogeneity and the exponential distribution of active sites and their energies indicate a multilayer sorption of the surface. The binding capacity and affinity between the adsorbent and phenol ions reach the highest value with high $\mathrm{KF}$ and $1 / \mathrm{n}$. Favorability of adsorption gives by the magnitude of the exponent $n$. As can be seen from Table 1 and Figure 4b, treated tea waste is a good adsorbent for phenol adsorption.

\section{Adsorption kinetics}

To evaluate the kinetics of the adsorption process, the experimental data were compared to those predicted by two kinetic models, the pseudo-first order and pseudo-second order. The pseudo first order equation can be expressed, as

$$
\log \left(q_{e}-q_{t}\right)=\log q_{e}-\frac{k_{1}}{2.303} t
$$

Where $q_{e}$ and $q_{t}$ the amount of adsorbate in mg at equilibri$\mathrm{um}$ at any time $\mathrm{t}, \mathrm{k}_{1}$ is the first order rate constant $\left(\mathrm{min}^{-1}\right)$. Rate constant, $\mathrm{k}_{1}$ and theoretical $\mathrm{q}_{\mathrm{e}}$ was calculated from the slope and intercept from the plot of $\log \left(\mathrm{q}_{\mathrm{e}}-\mathrm{q}_{\mathrm{t}}\right)$ versus $\mathrm{t}$, Figure $5 \mathrm{a}$

Pseudo-second order equation expressed as follow.

$$
\frac{t}{q_{t}}=\frac{1}{k_{2} q_{e}^{2}}+\frac{1}{q_{e}} t
$$

Where $\mathrm{k}_{2}$ is rate constant of second order adsorption. The linear plot of $\frac{t}{q_{t}}$ versus time gives $\frac{1}{q_{e}}$ as slope and $\frac{1}{k_{2} q_{e}^{2}}$ as intercepts, the linear plot pseudo-second-order model is shown in Figure $5 \mathrm{~b}$, Table 2 below.

Adsorption of phenol onto tea waste show rapid initial adsorption rate flowed by slower rate. Initially, the adsorption site is abundantly available, and phenol interacts easily, hence the higher rate of adsorption was observed. However, after initial periods lower adsorption may be due to slower diffusion of adsorbate into the interior adsorbent. The two kinetics models mentioned above has been used to understand the adsorption kinematics and correlation coefficient, $\mathrm{R}^{2}$. The linearity of these plots indicates the capacity of the two models. The correlation coefficient adsorption kinematics is 0.895 for untreated and 0.922 for treated adsorbents for pseudo first order and 1.001 .00 for second order respectively. The correlation coefficient shows that the pseudo-second-order models fit better to the experimental data for both treated and untreated tea waste.

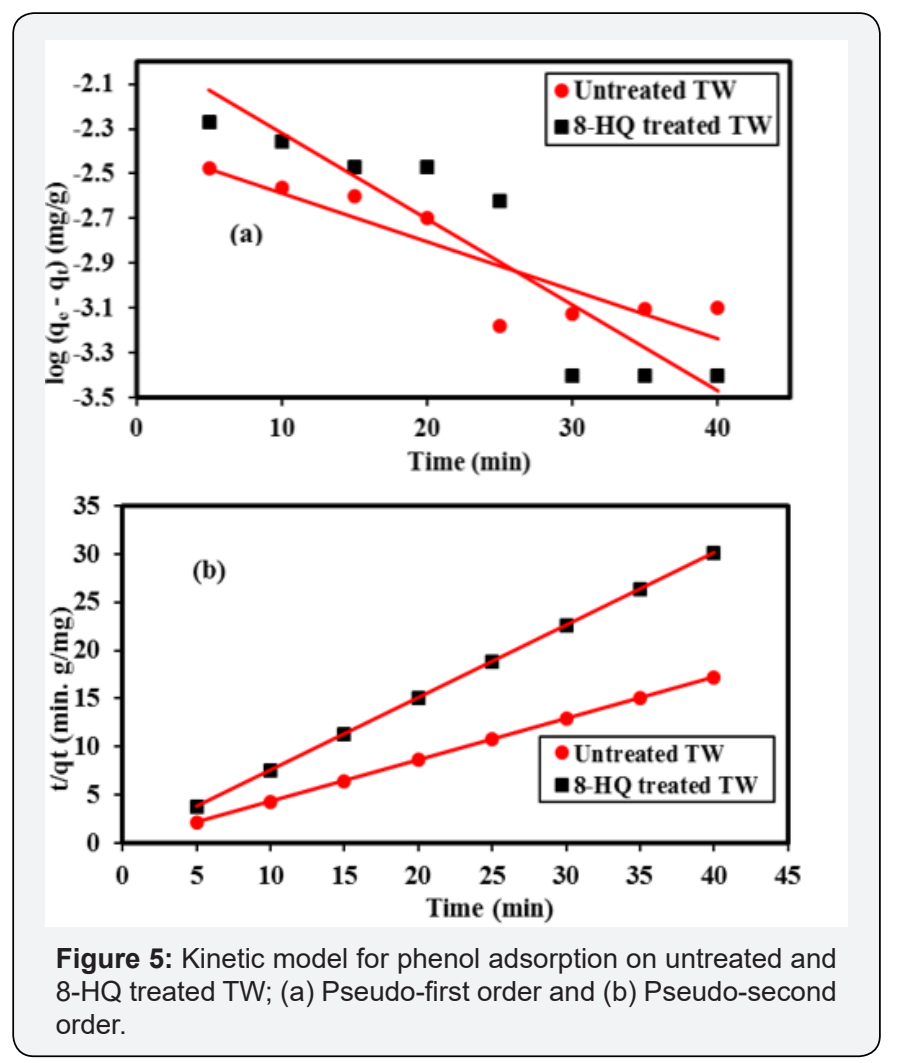

Table 2: Values of kinetic parameters on the adsorption of Phenol on modified and unmodified Tea Waste prepared adsorbent at room temperature.

\begin{tabular}{|c|c|c|}
\hline \multirow{2}{*}{ Kinetic Model \& Constants } & \multicolumn{2}{|c|}{ Values } \\
\cline { 2 - 3 } & UTW & 8-HQTW \\
\hline Pseudo-first order & \multicolumn{2}{|c|}{} \\
\hline qe (cal) & 0.862 & 0.661 \\
\hline k1 & 0.049 & 0.088 \\
\hline R2 & 0.895 & 0.922 \\
\hline Pseudo-second order & \multicolumn{2}{|}{} \\
\hline qe (cal) & 2.375 & 1.338 \\
\hline k2 & 37.72 & 17.722 \\
\hline R2 & 1 & 1 \\
\hline
\end{tabular}

\section{Conclusion}

Adsorption of phenol from aqueous solution was investigated experimentally using tea waste as an adsorbent. The batch experiment revealed that the equilibrium adsorption attained at 30 and 
25 minutes. The isothermal data were examined by employing two isotherm models, Langmuir, and Freundlich where the experimental data fitted very well to the Langmuir isotherm model indicating chemisorption of the adsorbate on powdered tea waste surface. Results of kinetics study indicate that the pseudo-second-order kinetics can simulate the adsorption process with a high accuracy for the adsorption of phenol from aqueous solution.

\section{Acknowledgment}

Authors thankfully acknowledge to the Department of Chemistry, College Natural Sciences, Jimma University, Jimma, for providing necessary facilities to carry out this work.

\section{References}

1. Arellano-Cárdenas $\mathrm{S}$, Gallardo-Velázquez T, Osorio-Revilla G, LópezCortéz Ma DS, Gómez-Perea B (2005) J Mex Chem Soc 49(3): 287.

2. Sabate J, Bayona JM, Solanas AM (2001) Chromosphere 44: 119.

3. Shemer H, Linden KG (2007) Aqueous photodegradation and toxicity of the polycyclic aromatic hydrocarbons fluorene, dibenzofuran, and dibenzothiophene. Water Res 41(4): 853-861.

4. Broholm MM, Broholm K, Arvin E (1991) Diffusion of heterocyclic compounds from a complex mixture of coal-tar compounds in natural clayey till. J Contam Hydrol 39(3-4): 227-247.

5. Meyer S, Carellie S, Stainhart H (1999) Simultaneous Determination of PAHs, Hetero-PAHs (N, S, O), and Their Degradation Products in Creosote-Contaminated Soils. Method Development, Validation, and Application to Hazardous Waste Sites. Anal Chem 71(18): 4023-4029.

6. Michałowicz J, Duda W (2007) Phenols - Sources and Toxicity. Polish J of Environ Stud 16(3): 347-362.

7. Anku WW, Mamo MA, Govender PP (2017) Phenolic Compounds: Natural Sources, Importance and Applications. In: Soto-Hernández, Intech Open, London, UK, pp. 419-443.

8. Mishra S, Bhattacharya J (2007) Malaysian Journal of chemistry 9(1): 51.

9. Gundogdu A, Duran C, Senturk HB, Soylak M, Ozdes D, et al. (2012) Adsorption of Phenol from Aqueous Solution on a Low-Cost Activated Carbon Produced from Tea Industry Waste: Equilibrium, Kinetic, and Thermodynamic Study. J Chem Eng Data 57(10): 2733-2743.

10. Jadhav DN, Vanjara AK (2004) Removal of phenol from wastewater using sawdust, polymerized sawdust and sawdust carbon. Indian J Chem Tech 11: 35-41.
11. Villegas LGC, Mashhadi N, Chen M, Mukherjee D, Taylor KE, et al. (2016) A Short Review of Techniques for Phenol Removal from Wastewater. Current Pollution Reports 2(3): 157-167.

12. Mohammed RN (2017) Journal of Babylon University/Engineering Sciences 25: 1282.

13. Shah J, Jan MR, ul Haq A, Zeeshan M (2015) Equilibrium, kinetic and thermodynamic studies for sorption of $\mathrm{Ni}$ (II) from aqueous solutionusing formaldehyde treated waste tea leaves. Journal of Saudi Chemical Society 19: 301-310.

14. Pavlović MD, Nikolić IR, Milutinović MD, Dimitrijević-Branković SI, Šiler-Marinković SS, et al. (2015) Plant waste materials from restaurants as the adsorbents for dyes. Hem Ind 69(6): 665-667.

15. Seungmann S, Dongsu K (2005) Modification of Langmuir isotherm in solution systems-definition and utilization ofconcentration dependent factor. Chemosphere 58(1): 115-123.

16. Foo KY, Hameed BH (2010) Insights into the modeling of adsorption isotherm systems. Chem Eng J 156(1): 2-10.

17. Langmuir I (1916) The constitution and fundamental properties of solids and liquids. Part i. Solids. J Am Chem Soc 38(11): 2221-2295.

18. Vijayaran K, Padmesh TVN, Palamivelu K, Velan M (2006) Biosorption of nickel (II) ions onto Sargassum wightii: application of two-parameter and three-parameter isotherm models. J Hazard Mater 133(1-3): 304-308.

19. Kundu S, Gupta AK (2006) Arsenic adsorption onto iron oxide-coated cement (IOCC): Regression analysis of equilibrium data with several isotherm models and their optimization. Chem Eng J 122(1-2): 93-106.

20. Pérez-Marín AB, Zapata VM, Ortuño JF, Aguilar M, Sáez J, et al. (2007) Removal of cadmium from aqueous solutions by adsorption onto orange waste. J Hazard Mater 139(1): 122-131.

21. Freundlich HMF (1906) Over the Adsorption in Solution. J Phys Chem 57: 385-471.

22. Adamson AW, Gast AP (1997) Physical chemistry of surface. ( $6^{\text {th }}$ edn), Wiley- inter science, New York, USA.

23. Zaldowitsch J (1934) über Den Mechanismus der Katalytischen Oxidation Von CO a $\mathrm{MnO}_{2}$. Acta Physico Chim URSS 1(2): 364-449.

24. Ahmaruzzamam M (2008) Adsorption of phenolic compounds on lowcost adsorbents: A review. Adv colloid interface Sci 143(1-2): 48-67.

Your next submission with Juniper Publishers will reach you the below assets

- Quality Editorial service

- Swift Peer Review

- Reprints availability

- E-prints Service

- Manuscript Podcast for convenient understanding

- Global attainment for your research

- Manuscript accessibility in different formats

( Pdf, E-pub, Full Text, Audio)

- Unceasing customer service

Track the below URL for one-step submission https://juniperpublishers.com/online-submission.php 